\title{
Continuous caudal epidural anaesthesia for vaginal hysterectomy in a patient of heart disease and severe spinal deformity; a case report
}

\author{
Ashok Jadon*, Swastika Chakraborty, Neelam Sinha and Sunil Kedia \\ *Correspondence: ashok.jadon@tatamotors.com \\ Department of Anaesthesia Tata Motors Hospital, Jamshedpur-831004, Jharkhand, India.
}

\begin{abstract}
We present this case report where we have used fluoroscopic localization of caudal space and caudal epidural catheter placement to conduct caudal epidural anaesthesia in a case of vaginal hysterectomy and colporrhaphy with co-morbidity of severe spinal deformity, valvular heart disease and pulmonary hypertension.
\end{abstract}

Keywords: Caudal epidural block, fluoroscopic guided, vaginal hysterectomy, kyphoscoliosis, valvular heart disease, pulmonary hypertension

\section{Introduction}

Caudal epidural anaesthesia has been used successfully in adult patients either as primarily sole anaesthetic technique, [1] adjuncts to general anaesthesia to provide postoperative analgesia [2,3]. In adult female patients, caudal epidural anaesthesia for vaginal hysterectomy has been suggested in anaesthesia literature [4]. However, is not a popular anaesthetic technique in adult patients due to anatomical difficulties in procedure and uncertainty of effect in adult patients $[5,6,7]$. Recent literature suggests that caudal epidural anaesthesia is again gaining acceptance for adults particularly for anorectal and minor gynaecological surgery which provides early ambulation and higher satisfaction $[\mathbf{8 , 9}]$. Due to availability of fluoroscopy and ultrasound for easy localization, this technique is frequently used for caudal steroid injection in adult patients as interventional pain management tool to treat sciatica $[10,11,12]$. In present case report, we used this technique for vaginal hysterectomy in adult female because conventional epidural or spinal anaesthesia was not feasible and general anaesthesia was considered more risky due to her existing cardiac disease.

\section{Case Report}

A female 47 years of age and $60 \mathrm{~kg}$ weight with prolapsed uterus was scheduled for vaginal hysterectomy and colporrhaphy. She has history of rheumatic heart disease and had corrective surgery for atrial septal defect (ASD) \& ventricular septal defect (VSD) in 1985. On examination; ant chest wall showed scar of previous cardiac surgery, thoracic cage was abnormal with crowding of ribs and spine has severe kypho-scoliosis of thoracolumbar spine. Spinal landmarks could not be palpated below $\mathrm{T} 1 / \mathrm{T} 2$ level. Whole lumber area showed a bony mass on the left side and no bony landmark in the midline or on the right side
(Figure 1). Landmarks for caudal anaesthesia were well defined. She was dyspnoeic, Heart rate was $96 / \mathrm{min}$ and Blood pressure was $140 / 86 \mathrm{mmHg}$. Airways assessment showed no abnormality. On chest auscultation air entry was adequate on both sides but occasional rhonchai and crepitations were present.

Previous physician (cardiologist) advised Tablet Spironolactone (20mg) daily and Tablet Digoxin (0.25) $1 / 2$ tab daily and steroid inhaler, which she was not taking. Routine blood and urine investigations were normal, current echocardiography showed severe tricuspid regurgitation, mild aortic and mitral regurgitation and pulmonary hypertension along with dilated aortic root, right atrium and diastolic dysfunction. X-rays of spine showed severe deformity of spinal anatomical structures at lumbar as-well- as thoracic area (Figure 2 and Figure 3). She was advised to take prescribed medicines along with course of antibiotics and was reviewed after two weeks. Chest condition was improved and she was scheduled for surgery.

One day before scheduled day of surgery, after informed consent and discussion about anaesthesia choices and associated risks, she was taken to operation theatre for anatomical assessment of spinal structure for possibility of fluoroscopic guided regional anaesthesia (spinal or epidural). Except identifiable caudal space, spinal structures could not be identified for safe conduct of spinal or epidural block. Finally plan for fluoroscopic guided caudal anaesthesia with catheter technique was made.

Next day in operation theatre (OT), intravenous fluid was started, monitors were connected and she was positioned prone on OT table. After cleaning and draping the area and with due a-septic precautions, caudal space was identified in lateral fluoroscopic view (Figure 4a). Skin and sub cutaneous tissue was infiltrated with $2 \mathrm{ml}, 1 \%$ lidocaine with $26 \mathrm{G}$ hypodermic needle at entry point and $19 \mathrm{G}$ tuohy needle was inserted at 

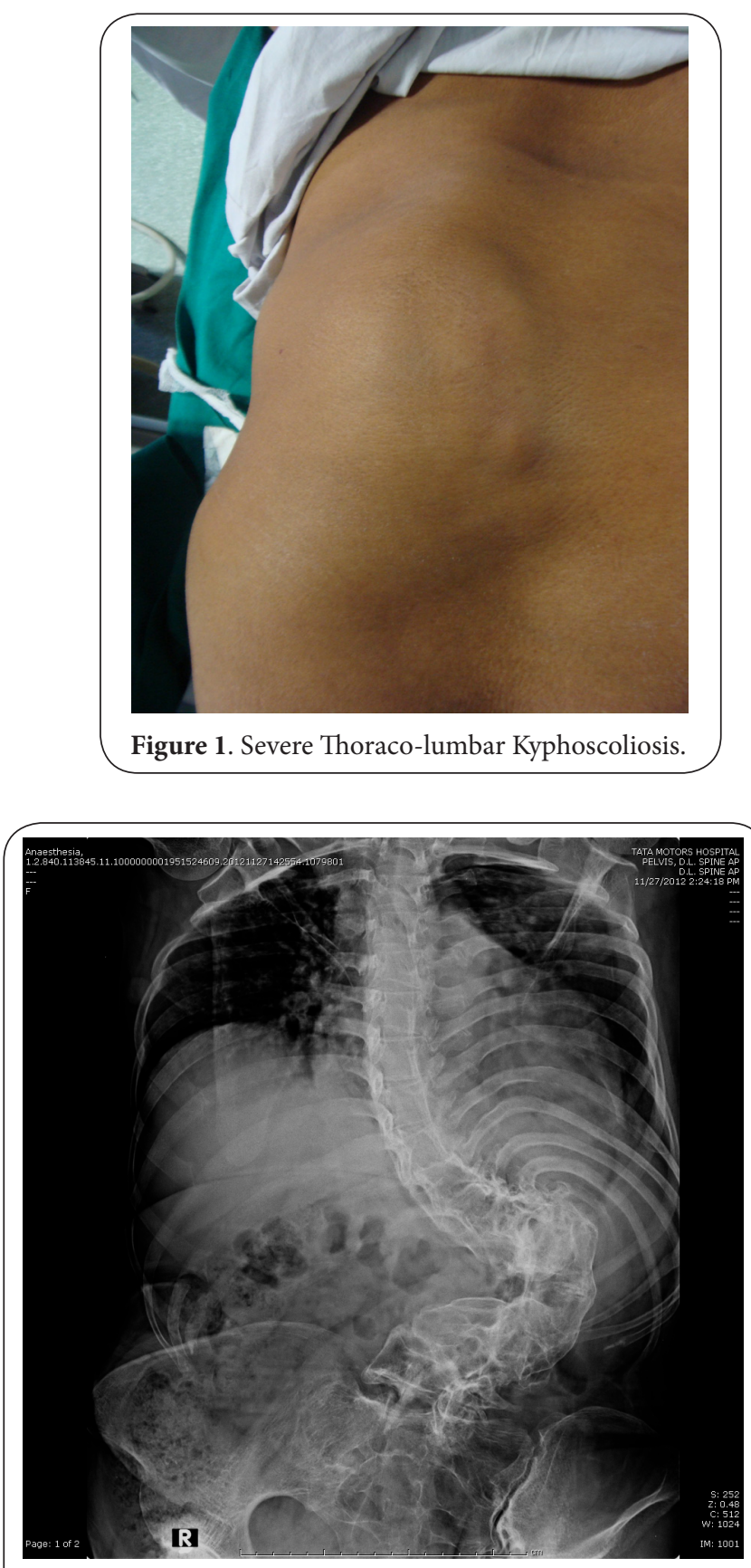

Figure 2. AP view of spine showing diffuse degenerative changes with structural deformity.

about $45^{\circ}$ in caudal space and $1 \mathrm{ml}$ water soluble contrast was injected to confirm proper needle position (Figure $4 \mathbf{b}$ ) than a flexible tip, wire reinforced epidural catheter was inserted up to $10 \mathrm{~cm}$ mark (Figure $5 \mathrm{a}$ ) and proper position (insertion level up to sacral promontory and no vascular injection) was confirmed by $1 \mathrm{ml}$ contrast injection through catheter (Figure 5b). Catheter was secured with adhesive tape and patient was turned supine. Epidural injection of $10 \mathrm{ml} 0.75 \%$ Ropivacaine was given. After 15 minutes sensory level up to L1/

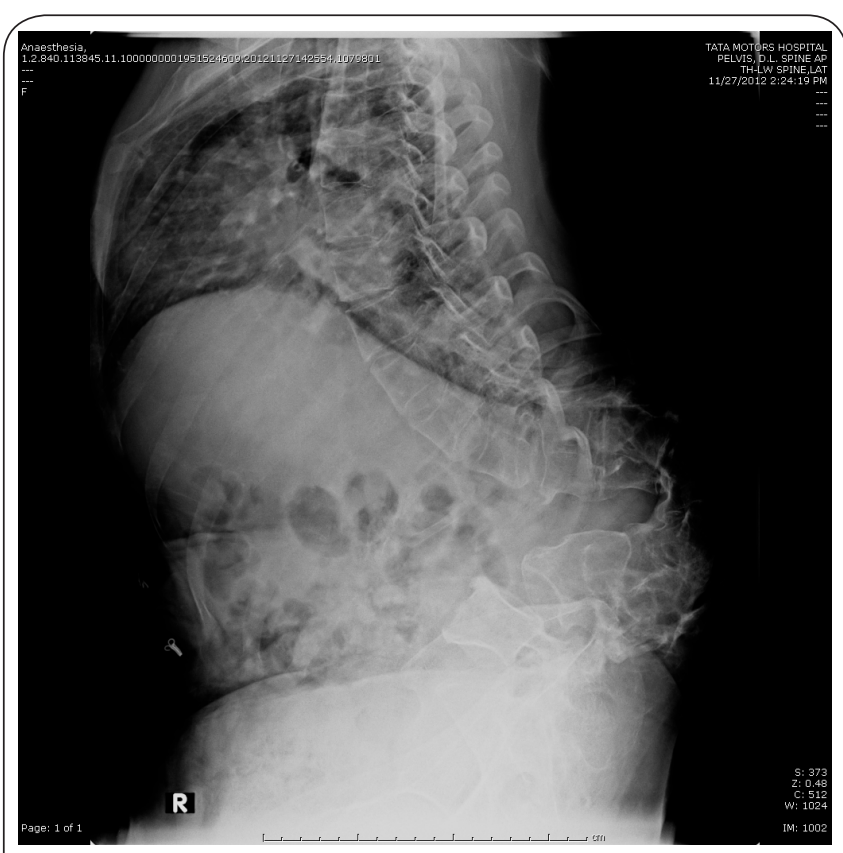

Figure 3. Lateral View of spine.

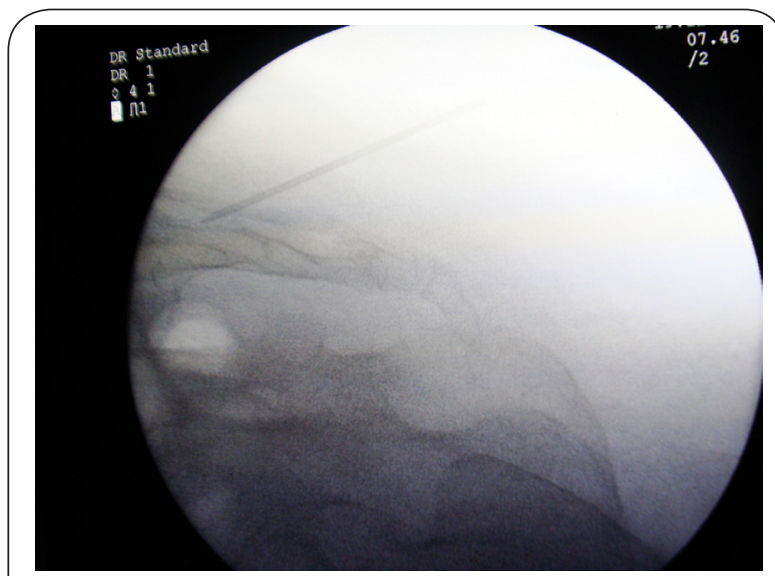

Figure 4a. Tuohy epidural needle in caudal space.

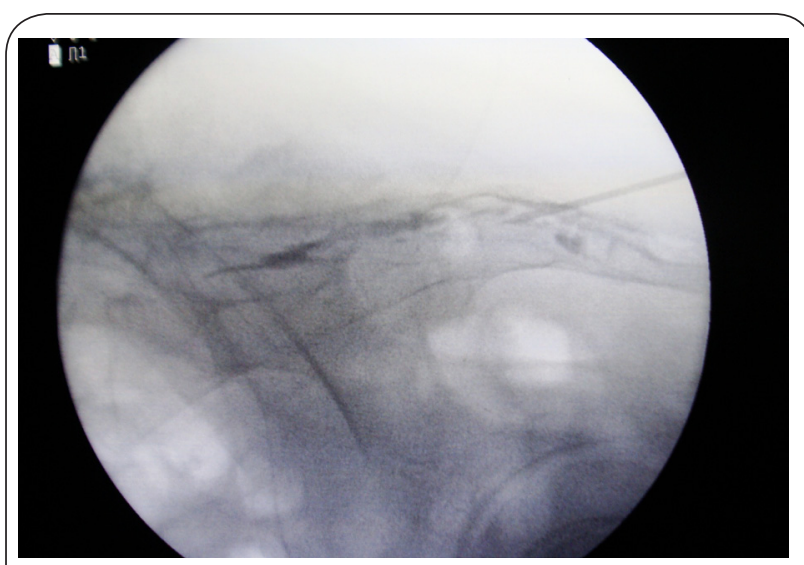

Figure $\mathbf{4 b}$. Leaner spread of contrast in caudal space. 


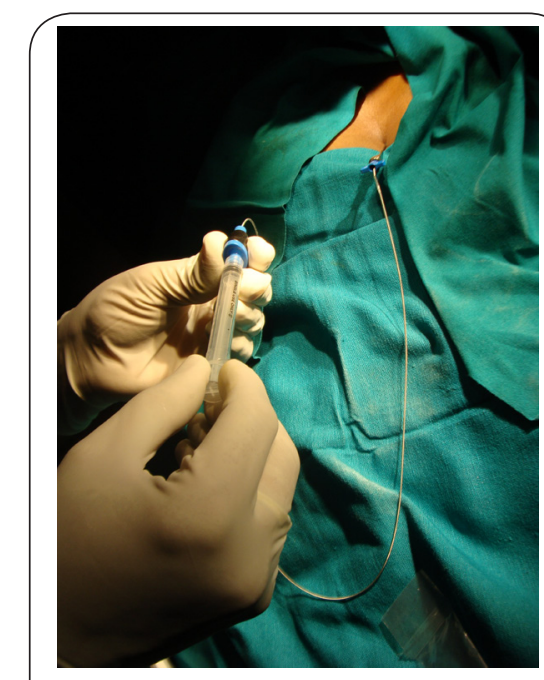

Figure 5a. Caudal epidural catheter inserted in epidural space through Tuohy needle.

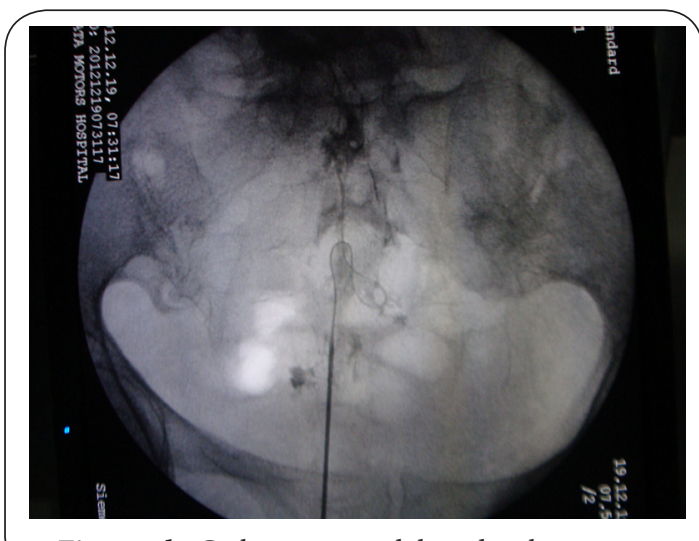

Figure 5b. Catheter in caudal epidural space.

L2 was achieved. Intravenous sedation with Inj. Fentanyl 50mic and Midazolam 1.0mg was given and patient was positioned in lithotomy position. Another $10 \mathrm{mlof} 0.75 \%$ Ropivacaine was given to attain level up to T8. Surgery was uneventful (surgical time $130 \mathrm{~min}$ ), blood loss $200 \mathrm{ml}$, she received $1.5 \mathrm{~L}$ crystalloid fluids during operation and required two doses of Inj. ephedrine (6mg each) to maintain BP. Postoperatively she was managed in HDU (high dependency unit) where continuous monitoring of vitals was done. Visual analogue score (VAS) was done hourly for first four hour and than fourhourly for $48 \mathrm{hrs}$. Post-operative analgesia was provided with epidural injection of $3 \mathrm{mg}$ preservative free $\mathrm{Inj}$. Morphine $+3 \mathrm{ml}$ $0.2 \%$ ropivacaine whenever VAS was more than 3 . Injection Paracetamol $1 \mathrm{G}$ intravenous (IV) was advised to use if, pain relief is not achieved within 30minutes of epidural injection. Good analgesia was achieved with epidural analgesia only; each dose gave relief for more than 10-12 hrs on first 24 hours and more than 20 hours for next 24 hrs. After that, epidural catheter was removed and analgesia was provided with oral analgesics Tab. Paracetamol (500mg) and Tramadol (50mg) orally. Patient was discharged home on $5^{\text {th }}$ post-operative day.

\section{Discussion}

Vaginal hysterectomy can easily be done under either general anaesthesia or central neuraxial block like spinal or epidural anaesthesia. We routinely do our cases of vaginal hysterectomy under combined spinal- epidural anaesthesia except when there is a contraindication or patient refusal for regional anaesthesia. Fluoroscopic guided injection of spinal or epidural is one of the options with technically difficult spinal [13]. However, identifiable structures and targets are prime requisite for safe outcome $[14,15]$. In present case spinal and epidural anaesthesia were not feasible; as even during fluoroscopy spinal structure could not be identified. General Anaesthesia with relaxant is our second choice with either LMA or endotracheal tube. General anaesthesia (GA) could have been used in this case however; it was not considered as a second choice due to pulmonary hypertension and multiple valvular dysfunctions. She had also features of congestive cardiac failure for which medicines were advised. In this situation GA was not considered safer than regional anaesthesia [16]. Caudal anaesthesia was the safe option in given circumstances provided, successful localization and satisfactory anaesthetic effect is achieved. In present case we used fluoroscopy for localization of caudal space and catheter placement for ensuring successful localization and correct catheter placement to achieve successful block with less amount of local anaesthetic. A recent study of 172 women undergoing minor gynaecologic surgery using caudal anaesthesia with $20 \mathrm{~mL}$ of $1.5 \%$ lidocaine, the highest sensory dermatome level reached was below $\mathrm{T}^{1} 0^{9}$. We used $20 \mathrm{mlof}$ $0.75 \%$ ropivacaine to achieve T8 level of sensory block and excellent relaxation to provide comfortable surgical condition. Caudal injection with anatomical landmarks results in high failure rates and requires large dosage of local anaesthesia for desired effect $[4,11,17]$. Injection without catheter could be a cause of high failure rates of caudal epidural due to escape of drug through sacral foramina [6]. In our case possibly due to abnormal spinal canal and catheter placement higher up in caudal space might have helped to achieve higher block with less amount of local anaesthetic drug. Anaesthesia literature also have mentioned that vaginal hysterectomy can be done under caudal epidural block and if catheter technique is used total dosage of local anaesthesia can be reduced up to $1 / 3$ compared to single injection technique [4]. We report this case because, we could not find similar situation in anaesthesia literature where caudal epidural was used as rescue technique for vaginal hysterectomy when other regional approaches were not feasible and GA was not safe. One report of continuous caudal block with caudad catheterization has been mentioned in literatures for vaginal operation in which catheter was inserted at L5/S1 and guided downwards to achieve caudal epidural anaesthesia [18]. However; we could not find any exclusive 
report or literature regarding use of fluoroscopy for successful caudal epidural anaesthesia for vaginal hysterectomy with or without caudal epidural catheter in difficult anatomy of spine.

\section{Conclusion}

We used caudal epidural anaesthesia with epidural catheter successfully to manage a case of vaginal hysterectomy in which spinal or lumber epidural anaesthesia was not feasible due to severe spinal deformity and general anaesthesia was considered unsafe due to cardiac disease.

Limitation of this case report: This case report of single case only suggests that, in clinical scenario wherever, situation is not conducive to either general anaesthesia or commonly used technique like epidural or spinal, caudal anaesthesia can be tried for vaginal hysterectomy. However, this technique is not the first choice because of inconsistent quality of block as suggested in literature. Fluoroscopic guided epidural or spinal can still be tried first if, anatomy of spine is clinically difficult.

\section{Competing interests}

The authors declare that they have no competing interests.

\section{Publication history}

Received: 29-Jan-2013 Revised: 7-Feb-2013

Re-Revised: 11-Feb-2013 Accepted: 15-Feb-2013

Published: 19-Feb-2013

\section{References}

1. Shah AS, Choudhary ZA: Is caudal epidural anesthesia effective for anorectal surgery?. Pak J Med Health Sci. 2007, 1:9-10.

2. Kita T, Maki N, Song Y S, Arai F and Nakai T: Caudal epidural anesthesia administered intraoperatively provides for effective postoperative analgesia after total hip arthroplasty. J Clin Anesth 2007, 19:204-8. | Article | PubMed

3. Van Elstraete A C, Pastureau F, Lebrun T and Mehdaoui H: Caudal clonidine for postoperative analgesia in adults. Br J Anaesth 2000, 84:401-2. | Article | PubMed

4. Southworth $\mathrm{J} L$ and Hingson R A: Continuous Caudal Analgesia in Surgery. Ann Surg 1943, 118:945-70. | Article I PubMed Abstract I Pubmed Full $\underline{\text { Text }}$

5. Drips R, Eckenhoff J, Vandam L, eds: Peridural and caudal anesthesia. In: Introduction to Anesthesia: The Principles of Safe Practice. Philadelphia, Pennsylvania: W.B. Saunders Company. 1982:229-234.

6. Black M G: Anatomic reasons for caudal anesthesia failure. Curr Res Anesth Analg 1949, 28:33-9. | PubMed

7. Murphy TM: Spinal, epidural, and caudal anesthesia: In: Miller RD, eds. Anesthesia. New York: Churchill Livingstone. 1986, 2:1102.

8. Siddiqui Z I, Denman W T, Schumann R, Hackford A, Cepeda M S and Carr D B: Local anesthetic infiltration versus caudal epidural block for anorectal surgery: a randomized controlled trial. J Clin Anesth 2007, 19:269-73. I Article I PubMed

9. Wong S Y, Li J Y, Chen C, Tseng C H, Liou S C, Tsai S C, Kau Y C and Wong K $\mathrm{M}$ : Caudal epidural block for minor gynecologic procedures in outpatient surgery. Chang Gung Med J 2004, 27:116-21. | Pdf I PubMed

10. Botwin K P, Thomas S, Gruber R D, Torres F M, Bouchlas C C, Rittenberg J J and Rao $S$ : Radiation exposure of the spinal interventionalist performing fluoroscopically guided lumbar transforaminal epidural steroid injections. Arch Phys Med Rehabil 2002, 83:697-701. I Article I PubMed

11. Renfrew D L, Moore T E, Kathol M H, el-Khoury G Y, Lemke J H and Walker C W: Correct placement of epidural steroid injections: fluoroscopic guidance and contrast administration. AJNR Am J Neuroradiol 1991, 12:1003-7. | Article | PubMed
12. Chen C P, Tang S F, Hsu T C, Tsai W C, Liu H P, Chen M J, Date E and Lew H L: Ultrasound guidance in caudal epidural needle placement. Anesthesiology 2004, 101:181-4. I Article I PubMed

13. Eidelman A, Shulman MS and Novak GM: Fluoroscopic imaging for technically difficult spinal anesthesia. J Clin Anesth 2005, 17:69-71. I Article | PubMed

14. Lirk P, Messner H, Deibl M, Mitterschiffthaler G, Colvin J, Steger B, Rieder $\mathrm{J}$ and Keller C: Accuracy in estimating the correct intervertebral space level during lumbar, thoracic and cervical epidural anaesthesia. Acta Anaesthesiol Scand 2004, 48:347-9. I Article I PubMed

15. Rathmell JP and Manion SC: The role of image guidance in improving the safety of pain treatment. Curr Pain Headache Rep 2012, 16:9-18. | Article I PubMed

16. Fischer LG, Van Aken $\mathrm{H}$ and Burkle $\mathrm{H}$ : Management of pulmonary hypertension: physiological and pharmacological considerations for anesthesiologists. Anesth Analg 2003, 96:1603-16. | Article I PubMed

17. Barham $G$ and Hilton A: Caudal epidurals: the accuracy of blind needle placement and the value of a confirmatory epidurogram. Eur Spine $J$ 2010, 19:1479-83. | Article | PubMed Abstract | Pubmed Full Text

18. Chung YT, Lin CH, Pang WW, Yeh LT and Tien YK: An alternative continuous caudal block with caudad catheterization via lower lumbar interspace in adult patients. Acta Anaesthesiol Sin 1998, 36:221-7. | Article | PubMed

\section{Citation:}

Jadon A, Chakraborty S, Sinha N and Kedia S: Continuous caudal epidural anaesthesia for vaginal hysterectomy in a patient of heart disease and severe spinal deformity; a case report. journal of Anesthesiology and Clinical Science 2013, 2:15. http://dx.doi.org/10.7243/2049-9752-2-15 